\title{
EDUCAÇÃO NA SOCIEDADE DO CAPITAL - ELEMENTOS PARA UMA ANALISE
}

EDUCATION IN CAPILALIST SOCIETY - SUBJECTS TO ANALYSE

\author{
Adriana Alves da Silva ${ }^{1}$ \\ Elenilce Gomes de Oliveira ${ }^{2}$ \\ Enéas Arrais Neto ${ }^{3}$
}

\section{RESUMO}

Neste texto, elencam-se aspectos importantes das categorias trabalho e alienação/estranhamento, da perspectiva marxista, visando a contribuir num alcance maior de compreensão no que se refere à critica cotidiana da educação. Espera-se que a reflexão aqui expressa possa contribuir com subsídios para que a educação possa ser discutida sob uma perspectiva crítica, como elemento importante no desenvolvimento da sociabilidade humana, não podendo, portanto, seu desenvolvimento ser privilégio de ascensão pessoal de pessoas singulares.

Palavras-chave: Educação - Trabalho - Alienação.

\section{ABSTRACT}

In this paper, we list important aspects of categories such as job and alienation/estrangement, in the Marxist perspective, aiming to contribute for a better understanding of the criticism in education. We expect that the reflection expressed here may provide other elements in search of discuss the education in a critical perspective, as an important subject in the development of human sociability and not such as an individual prerogative.

Keywords: Education - Labor - Alienation.

\section{INTRODUÇÃO}

Cotidianamente, ouvimos discursos que analisam a educação como redenção e instrumento de ascensão social. Grande parte desses discursos reivindica a qualidade da infraestrutura, formação dos professores e maior compromisso na apresentação dos conteúdos, utilizando-se muitas vezes de casos isolados de projeção, para exemplo de que a educação mesmo diante de todas as adversidades seria um meio para a promoção social. Esses discursos, superficiais em seus argumentos, elegem a singularidade, esquecendo os 
nexos e as determinações históricas da sociedade de classe, contribuindo para mascarar a exclusão e a desigualdade, naturalizando as relações sociais.

Compreendemos que várias são as matrizes teórico-metodológicas que se propõem a analisar a educação na atualidade, contudo, visando a uma apropriação crítica, optamos por investigá-la a partir da perspectiva marxista, sendo portanto o objetivo, nesse ensaio, exibir alguns elementos que nos auxiliam a compreender a educação como elemento importante no processo de construção e transformação da ordem social.

A escolha da perspectiva marxista justifica-se em virtude de que nos permite ampliar o horizonte de análise, situando a educação na totalidade das relações sociais estabelecidas cotidianamente, num processo que possibilita a leitura e compreensão das múltiplas e contraditórias determinações da realidade em que está inserida, como reação dialética entre objetividade e subjetividade, cujo propósito se expressa na construção, transformação e humanização da sociedade.

No texto que segue, desenvolvemos esse ponto, elegendo aspectos das categorias, trabalho e alienação, como ferramentas importantes para pensar e analisar a educação na sociedade capitalista. Tencionamos identificar contradições e possibilidades de sua realidade, do ponto de vista da contribuição para a autonomia da sociedade, subvertendo os discursos e debates cotidianos de forma superficial.

Cabe destacar o fato de que a analise aqui estabelecida tem 0 entendimento da sua limitação e não pressupõe captar ou exaurir todos os aspectos da totalidade envolvida, mas apreender a educação como momento da totalidade concreta, buscando elementos que possam contribuir para um exame mais fundamentado, e para a qualificação das reflexões e dos debates.

\section{TRABALHO - CATEGORIA IMPRESCINDÍVEL NO ENTENDIMENTO DA EDUCAÇÃO}

A educação é uma atividade eminentemente humana e, cotidianamente, o homem se utiliza desta para auxiliar nas ações de garantia de suas necessidades, sejam essas materiais ou espirituais. Assim, para estabelecimento de uma análise da educação, de fundamental importância se 
faz o entendimento do processo pelo qual os homens garantem essa existência e afirmam-se homens, distinguindo-se dos demais seres naturais - entender, portanto, o trabalho.

Conforme Marx é no trabalho e pelo trabalho que o homem se constitui ser social. Diferentemente dos demais seres naturais, ele marca seu desenvolvimento desde o momento em que, para garantir a sua existência biológica, se distingue da natureza, ampliando suas formas de retirar desta os elementos básicos da sua sobrevivência, adaptando-a a si conforme suas necessidades:

Podemos distinguir o homem dos animais pela consciência, pela religião ou por qualquer coisa que se queira. Porém, o homem se diferencia propriamente dos animais a partir do momento em que começa a produzir seus meios de vida, passo este que se encontra condicionado por sua organização corporal. Ao produzir seus meios de vida, o homem produz indiretamente sua própria vida material. (MARX E ENGELS, 1987, p. 19).

Mediante o trabalho, a natureza se humanizou, dando origem à vida social, proporcionando condições avançadas de conforto e bem-estar. Pela atividade humana, e a capacidade de fabricar instrumentos, cada vez mais o homem evoluiu e se distancia da necessidade de atuação direta sobre a matéria natural, melhor utilizando o uso do tempo e propiciando facilidade na execução de tarefas de sobrevivência.

Aspecto importante reporta-se ao fato de o trabalho não ser uma atividade genética, nem o homem predispor em sua condição genética de habilidades e conhecimentos para transformação da natureza. Estas características são adquiridas com a repetição e experimentação nas suas ações cotidianas, sendo estas transmitidas mediante aprendizado. Esta característica fundamental evita que os homens tenham sempre de voltar à forma de trabalho mais elementar, possibilitando, ao contrário, o aperfeiçoamento dos instrumentos e evolução humana com origem nas gerações anteriores. Na explicação de Saviani (2007, p. 154),

Se a existência humana não é garantida pela natureza, não uma dádiva natural, mas tem de ser produzida pelos próprios homens, sendo, pois, um produto do trabalho, isso significa que o homem não nasce homem. Ele forma-se homem. Ele não nasce sabendo 
produzir-se como homem. Ele necessita aprender a ser homem, precisa aprender a produzir sua própria existência.

Depreende-se, portanto, que, ao transformar a natureza pela ação do trabalho, o homem desenvolveu a capacidade teleológica de primeiro idealizar, para depois concretizar suas objetivações, podendo nestas visualizar possibilidades outras, fato que o distingue como ser inacabado e em constante transformação.

Pelo desenvolvimento de conhecimentos e habilidades, o trabalho, por mais simples que seja, não se limita à experiência pessoal de uma pessoa, mas se realiza na base da experiência e da prática social coletiva, não atendendo a um elenco limitado e invariável de necessidades, implicando, ao contrário, o desenvolvimento de novas possibilidades (NETTO E BRAZ, 2010, p. 31).

O trabalho consubstancia-se, dessa forma, numa relação entre o homem e a natureza:

Antes de tudo, o trabalho é um processo entre o homem e a Natureza, um processo em que o homem, por sua própria ação, media, regula e controla seu metabolismo com a Natureza. Ele mesmo se defronta com a matéria natural como uma força natural. Ele põe em movimento as forças naturais pertencentes à sua corporalidade, braços e pernas, cabeças e mão, a fim de apropriar-se da matéria natural como forma útil para sua própria vida. Ao atuar, por meio desse movimento, sobre a Natureza externa a ele e ao modificá-la, ele modifica, ao mesmo tempo, sua própria natureza (MARX, 2004, p. 211).

Pelo exposto, podemos inferir que o trabalho é uma atividade coletiva, realizada por sujeitos que prefiguram o resultado de sua ação, não obedecendo apenas a determinismos orgânico-naturais, ou gregarismo de raízes naturais. Parte das necessidades de superação das condições materiais objetivadas na relação do homem com a natureza e se estende além destas, no estabelecimento de relações sociais fundamentais, que implicam a transmissão e aprendizagem de habilidades e conhecimentos e, portanto, em educação.

O trabalho privilegia, assim, um princípio educativo que auxilia 0 homem a compreender o processo histórico e social no qual está inserido, 
ampliando as capacidades, potencialidades e sentidos humanos. Nesta direção, explica Ramos (2010, p.09):

[...] o trabalho, como princípio educativo, está na base de uma concepção epistemológica e pedagógica, que visa a proporcionar aos sujeitos a compreensão do processo histórico de produção científica, tecnológica e cultural dos grupos sociais, considerada como conhecimentos desenvolvidos e apropriados socialmente, para a transformação das condições naturais da vida e para a ampliação das capacidades, das potencialidades e dos sentidos humanos.

Ao comportar as ações realizadas pelos sujeitos, as quais ora relacionam o homem à natureza na produção de bens materiais, ora conectam os homens entre si na produção de relações de caráter imaterial/subjetivo, a sociabilidade humana/sociedade situa o homem para além da natureza, caracterizando-o como ser com capacidade para escolher, projetar, objetivarse, desprendendo-se do imediato, da singularidade dos fenômenos, tornandose assim universal.

Em verdade, pela capacidade teleológica de objetivar-se, seja de forma material ou de modo imaterial, o homem se revela como ser criativo e autoprodutivo: ser da práxis, produto e criação da sua autoatividade, "ele é o que(se) fez e (se)faz" (NETTO E BRAZ, 2010, p. 43).

Nesse sentido, e pelas objetivações possuírem o caráter coletivo e de processo, evoluindo continuamente, essas objetivações devem estar disponibilizadas de forma democrática a todos, assimilando-as e apropriandoas, cada homem, de forma singular, por aproximação e escolha, apropriação esta, em que reside a constituição da sua subjetividade.

Cabe ressaltar o fato de que a originalidade de cada individuo social (originalidade que deve nuclear sua personalidade) depende das condições e oportunidades vivenciadas, nas quais cada homem pode se apropriar do maior numero de objetivações. Muito embora sejam as objetivações elaborações coletivas, porém, devendo, portanto, estar disponibilizadas para todos, esta condição não é garantia de que sua apropriação ocorra por meio dos homens singulares.

Este processo - Educação - tem papel fundamental, já que se expressa pelo resultado das ações de todo o meio sociocultural sobre os seus participantes. Corroborando Libâneo (1994, p.17), a educação é o "processo de 
prover os indivíduos dos conhecimentos e experiências culturais que os tornam aptos a atuar no meio social e a transformá-lo em função de suas necessidades".

A educação se faz no cotidiano e envolve diversos espaços: família, igreja, organizações comunitárias, organizações de cultura, a política e a escola. Conforme Brandão (1995, p.47),

É o exercício de viver e conviver o que educa. E a escola de qualquer tipo é apenas um lugar e um momento provisórios onde isto pode acontecer. Portanto, é a comunidade quem responde pelo trabalho de fazer com que tudo o que pode ser vivido - e - aprendido da cultura seja ensinado com a vida - e também com a aula - ao educando.

É neste sentido, e nesta relação com o todo social, que a educação escolar é parte constitutiva indispensável para políticas que visam à participação de todos nos espaços sociais e políticos e, mesmo, para inserção no mundo profissional. É por isso que "hoje, praticamente, não há país no mundo que não garanta, em seus textos legais, o acesso de seus cidadãos à educação básica" (CURY, 2002, p.246).

E importante notar que, sendo a educação um fenômeno social, ou seja, parte integrante das relações sociais, econômicas, políticas e culturais da sociedade, sua prática não se faz dissociada de intencionalidade, mas sim socialmente determinada. Neste sentido, embora a educação se faça atendendo a uma necessidade de socialização, não constitui elemento neutro, mas determinado por fins e exigências sociais, políticas e ideológicas, ou seja, valores, normas e particularidades da estrutura social à que está subordinada, incluindo suas contradições. Assinala Ramos 2010, p. 69:

[...] produzimos nossa existência em contextos produtivos concretos, também configurados economicamente pelo modo de produção, e com características históricas correspondentes ao nível de avanço das forças produtivas e de contradições das relações sociais de produção. Tais características colocam, para os sujeitos, exigências específicas de domínio técnico-científico, para que se tornem aptos a produzir sua existência mediante a inserção nesses contextos. É nessa perspectiva que o trabalho se torna princípio educativo [num segundo sentido], ou seja, na medida em que coloca exigências específicas que o processo educativo deve preencher em vista da participação direta dos membros da sociedade no trabalho socialmente produtivo (grifo nosso). 
Constituindo a educação uma ação que propicia a vivência de experiências em contextos configurados pelo modo de produção no qual os homens se organizam para objetivação de suas necessidades, torna-se evidente que, em sociedades onde a propriedade privada se faz existir e as objetivações do trabalho não mais se constituem como produto democrático coletivo, a educação também reflita essa situação, tornando-se diferenciada de acordo com os estrátos e setores de classe nos quais acontece. Reflete, desta forma, o posicionamento dos vários grupos em conflito numa sociedade de classes.

O trabalho, pela própria acepção fundante da realidade, é uma atividade indispensável em qualquer modalidade de sociabilidade. Conforme já o percebia Marx,

O trabalho, como criador de valores-de-uso, como trabalho útil, é indispensável à existência do homem - quaisquer que sejam as formas de sociedade -, é necessidade natural e eterna de efetivar o intercâmbio material entre o homem e a natureza e, portanto, de manter a vida humana (MARX, 2004, p. 64-65).

Cabe assinalar contudo, que, muito embora o trabalho seja intrínseco à realização humana, nas sociedades de classe pode assumir um caráter ambíguo, ou seja, pode ser utilizado como instrumento de desenvolvimento das potencialidades do ser humano, mas, também, impedir esse desenvolvimento. Demonstra-se por um lado, como categoria mediadora do homem com a natureza, comum as pessoas, comportando a própria essência, sendo denominado por Marx de trabalho útil, trabalho concreto, que cria os valores de uso necessários ao ser humano para satisfazer socialmente as suas necessidades físicas e espirituais; de outra forma, sob o caráter de trabalho abstrato, trabalho como dispêndio de energia, se configura simplesmente como trabalho quantitativo, contido nas mercadorias, cujo principal fim é a criação de mais-valia, a valorização do valor, a reprodução e autovalorização do capital.

Com efeito, a condição de existência do homem, independente deste modelo de sociedade, está centrada no trabalho. Sem este, ele não pode viver, ou seja, sem produzir os meios de subsistência, não é possível pensar em qualquer forma de sociabilidade. Com efeito, muito embora a atual 
sociabilidade traga a marca da alienação e do estranhamento, essa não é uma condição fixa, ou única, do trabalho, podendo ser mudada como expressão das próprias contradições engendradas pela sociedade de classes com a qual se articula.

Na sociedade capitalista, o trabalho é expresso de forma alienada em relação ao trabalhador, impedindo que ele desenvolva plenamente suas potencialidades. Por sua vez, a educação tem papel fundamental no processo de compreensão e elaboração da realidade viabilizada pelo trabalho. $\mathrm{Na}$ atualidade, porém, em virtude das objetivações humanas terem sido produzidas no marco da sociedade de classes, caracterizadas pela divisão social do trabalho e apropriação privada das forças produtivas, a educação assume a forma desta sociedade alienada, mascarando as relações de dominação e exploração, apresentando a sociedade atual como processo natural e estruturado sem possibilidade de modificação.

\section{ALIENAÇÃO ${ }^{4}$ - A EXTERIORIZAÇÃO ESTRANHADA NA EDUCAÇÃO}

Na sociedade capitalista, marcada pela divisão social do trabalho e propriedade privada dos meios de produção, o produto da atividade humana, e dentro desta a educação, em vez de beneficiar a todos, passa a ser desenvolvida de forma desigual, privilegiando uma classe em detrimento de outra. Desse modo, o trabalho que garantiu ao homem a capacidade teleológica deixa de se mostrar como objetivações do trabalhador, para se exprimir como algo que lhe é estranho, fenômeno de inversão caracterizado com procedência na alienação.

A alienação, neste entendimento, reporta-se à relação do trabalhador com o seu trabalho, o qual deixa de se mostrar como objetivações que possuem características e identidade do trabalhador (singularidade), deixando também de espelhar aquilo que representa a humanidade (universalidade), passando a dominar o trabalhador, e expressando-se não como obra sua, mas sim como algo que lhe é estranho, em que o homem não se reconhece.

Primeiro, que o trabalho é externo ao trabalhador, isto é, não pertence ao seu ser, que ele não se afirma, portanto, em seu 
trabalho, mas nega-se nele, que não se sente bem, mas, infeliz, que não desenvolve nenhuma energia física e espiritual livre, mas mortifica sua physis e arruína o seu espírito. O trabalhador só se sente, por conseguinte e em primeiro lugar, junto a si [quando] fora do trabalho, e fora de si [quando] no trabalho. O seu trabalho não é, portanto, voluntário, mas forçado, trabalho obrigatório. $\mathrm{O}$ trabalho não é, por isso, a satisfação de uma carência, mas somente um meio de satisfazer necessidades fora dele. Sua estranheza evidencia-se aqui [de forma] tão pura que, tão logo inexista coerção física ou outra qualquer, foge-se do trabalho como de uma peste. $O$ trabalho externo, o trabalho no qual o homem se exterioriza, é um trabalho de auto-sacrifício, de mortificação. Finalmente, a externalidade do trabalho aparece para o trabalhador como se [o trabalho] não fosse seu próprio, mas de um outro, como se [o trabalho] não lhe pertencesse, como se ele no trabalho não pertencesse a si mesmo, mas a um outro. (...) Pertence a outro e é a perda de si mesmo. (MARX, 2008, p. 82-83).

Com efeito, o trabalhador passa a enxergar a realidade não mais como produção das condições materiais de existência - do trabalho - deixando a condição de sujeito a objeto, sentindo-se um ser estranho na sociedade que edifica. Alienado o trabalho, "a criatura passa então a dominar o criador", num fenômeno de inversão no qual o trabalho perde o caráter humanizador e, quanto mais o homem produz, mais ele se aliena, mais ele se desgasta física e espiritualmente, numa relação de estranhamento cujo produto aufere uma autonomia capaz de domina-lo (NETTO E BRAZ, 2010, p. 31).

Todas estas consequências derivam do facto de que o trabalhador se relaciona ao produto do seu trabalho como a um objeto estranho. Com base neste pressuposto, é claro que quanto mais o trabalhador se esgota a si mesmo, tanto mais poderoso se torna o mundo dos objetos, que ele cria perante si, tanto mais pobre ele fica na sua vida interior, tanto menos pertence a si próprio. (MARX, 2008, p.159).

Para Marx (2008), o trabalho alienado não se apresenta apenas na relação do trabalhador com o produto do seu trabalho. Nesse sentido, argumenta que a alienação é expressa em quatro aspectos inter-relacionados.

1. Alienação dos produtos do trabalho.

2. Alienação do ato da produção.

3. Alienação do ser genérico do homem.

4. Alienação do homem pelo próprio homem.

A alienação do trabalhador com o produto do seu trabalho mostra-se na falta de reconhecimento do homem de sua capacidade de se ver como ser criador, produtor. Nesse sentido, não mais encontra identidade com o resultado 
do seu trabalho, parecendo-Ihe este como uma coisa estranha que não lhe pertence. Assim, os objetos produzidos não servem para satisfazer suas necessidades, mas sim as de outrem.

A realização do trabalho surge de tal modo como desrealização que o trabalhador se invalida até à morte pela fome. A objetivação revela-se de tal maneira como perda do objeto, que o trabalhador fica privado dos objetos mais necessários, não só à vida, mas também ao trabalho. Sim, o trabalho transforma-se em objeto, que ele só consegue adquirir com o máximo esforço e com interrupções imprevisíveis. A apropriação do objeto manifesta-se a tal ponto como alienação que quanto mais objetos 0 trabalhador produzir tanto menos ele pode possuir e mais se submete ao domínio do seu produto, do capital. (MARX, 2008, p. 159).

Sem se reconhecer nos objetos que produziu, o trabalhador passa a ter com estes uma relação de autonomia e oposição. Com efeito, o trabalho, no lugar de trazer satisfação, desumaniza e oprime o trabalhador. Por isso, o trabalhador se torna um servo dos objetos que produz:

A alienação do trabalhador no seu produto significa não só que o trabalho se transforma em objeto, assume uma existência externa, mas que existe independentemente, fora dele e a ele estranho, e se torna um poder autônomo em oposição com ele; que a vida que deu ao objeto se torna uma força hostil e antagônica. (MARX, 2008, p. 160).

Alienação do ato da produção. Conforme Marx (2008), durante a produção, em virtude de a atividade a ser realizada ser determinada por outrem, ou seja, seu conteúdo e sua finalidade não são determinados pelo trabalhador, a alienação se manifesta do trabalhador consigo próprio, e, desta maneira, reflete no seu trabalho que lhe parecer alheio, como se não fosse seu.

[...] o trabalho é exterior ao trabalhador, quer dizer, não pertence à sua natureza; portanto, ele não se afirma no trabalho, mas nega-se a si mesmo, não se sente bem, mas infeliz, não desenvolve livremente as energias físicas e mentais, mas esgota-se fisicamente e arruína o espírito. Por conseguinte, o trabalhador só se sente em si fora do trabalho, enquanto no trabalho se sente fora de si. Assim, o seu trabalho não é voluntário, mas imposto, é trabalho forçado. Não constitui a satisfação de uma necessidade, mas apenas um meio de satisfazer outras necessidades. [...] O trabalho externo, o trabalho em que o homem se aliena, é um trabalho de sacrifício de si mesmo, de mortificação. [...] Chega-se à conclusão que o homem (o trabalhador) só se sente livremente activo nas suas funções animais - comer, beber e procriar, quando muito, na habitação, no adorno, etc. enquanto nas funções humanas se vê reduzido a animal. O elemento animal torna-se humano e o humano, animal. Comer, beber e 
procriar, etc., são também certamente genuínas funções humanas. Mas, abstractamente consideradas, o que as separa da restante esfera da actividade humana e as transforma em finalidades últimas e exclusivas é o elemento animal. (MARX, 2008, p. 162-163).

Nesse âmbito o trabalhador não se realiza, não sente satisfação no que faz e sua ação, enfim o brutaliza. Nesse sentido, que Marx enfatiza que o homem só aparecerá plenamente livre quando das suas atividades puramente animais, ou seja, comer, beber e procriar, de modo que se chega a recair na contradição "enquanto nas funções humanas se vê reduzido a animal. $O$ elemento animal torna-se humano e o humano animal". (MARX, 2008, p. 162).

O homem, porém, faz de sua atividade vital um objeto de sua vontade e consciência. Ele tem uma atividade vital consciente. Ela não é uma prescrição com a qual ele esteja plenamente identificado. A atividade vital consciente distingue o homem da atividade vital dos animais: só por esta razão ele é um ente - espécie. Ou antes, é apenas um ser autoconsciente, isto é, sua própria vida é um objeto para ele, porque ele é um ente espécie. Só por isso, a sua atividade é atividade livre. $\mathrm{O}$ trabalho alienado inverte a relação, pois o homem, sendo um ser autoconsciente, faz de sua atividade vital, de seu ser, unicamente um meio para sua existência. (MARX, 2008, p.84).

$\mathrm{Na}$ alienação do homem com relação ao seu ser genérico, constatase que ele fica destituído de sua característica universal, reduzindo-se a uma mera condição de vida individual, não se reconhecendo nas objetivações humanas, tão pouco imprimindo sua marca nestas objetivações.

Alienado da sua forma genérica, ele não logra se enxergar no outro, equalizando-se aos animais e perdendo, portanto, a capacidade de humanização. Por sua vez, a atividade laboral passa a ser apenas meio de sobrevivência individual, desprovida de concepção e essência humana potencialmente emancipadora, deixando de ser uma manifestação de sua essência para ser instrumento apenas para a fabricação de bens de sobrevivência:

[...] é precisamente na ação sobre o mundo objetivo que o homem se manifesta como verdadeiro ser genérico. Tal produção é a sua vida genérica ativa. Através dela, a natureza surge como a sua obra e a sua realidade. Por conseguinte, o objeto do trabalho é a objetivação da vida genérica do homem: ao não reproduzir-se apenas intelectualmente, como na consciência, mas ativamente, ele duplicase de modo real e intui o seu próprio reflexo num mundo por ele criado. Pelo que, na medida em que o trabalho alienado subtrai ao homem o objeto da sua produção, furta-lhe igualmente a sua vida genérica, a sua objetividade real como ser genérico, e transforma em 
desvantagem a sua vantagem sobre o animal, porquanto lhe é arrebatada a natureza, o seu corpo inorgânico. (MARX, 2008, p. 165166).

A alienação do homem em relação ao próprio homem sintetiza os demais aspectos da alienação desenvolvidos por Marx. O homem alienado do seu processo produtivo e do produto do seu trabalho, e ainda de seu ser genérico é, em verdade, o homem alienado de si mesmo. A auto-alienação se estabelece, pois, quando ele não se percebe como ser genérico, quando não se percebe no outro. Com efeito, uma vez que o produto e a atividade de uns pertencem a outros, este outro passa a ser visto como um concorrente, um rival e não como semelhante.

\begin{abstract}
Uma conseqüência imediata da alienação do homem a respeito do produto do seu trabalho, da sua vida genérica, é a alienação do homem relativamente ao homem. Quando o homem se contrapõe a si mesmo, entra igualmente em oposição com os outros homens. O que se verifica com a relação do homem ao seu trabalho, ao produto do seu trabalho e a si mesmo, verifica-se também com a relação do homem aos outros homens, bem como ao trabalho e ao objeto do trabalho dos outros homens. De modo geral, a afirmação de que o homem se encontra alienado da sua vida genérica significa que um homem está alienado dos outros, e que cada um dos outros se encontra igualmente alienado da vida humana (MARX, 2008, p. 166).
\end{abstract}

O trabalho alienado é intrínseco do sistema capitalista e, dentre os seus desdobramentos para obtenção de suas finalidades, encontram-se a propriedade privada e a divisão social do trabalho, dimensões estas que impedem, a um só tempo, que o trabalhador possa ter domínio da produção e, consequentemente, do produto do seu trabalho. Conforme observam Marx e Engels (1987, p. 46), a "divisão do trabalho e propriedade privada são expressões idênticas: a primeira enuncia em relação à atividade aquilo que se enuncia na segunda em relação ao produto da atividade".

Estando o trabalhador separado dos meios de produção e dispondo apenas de seu trabalho, não vê alternativa para garantir a sua sobrevivência a não ser estabelecer uma relação com outro que está fora do processo de trabalho (o detentor dos meios de produção) em troca de um salário, não tendo, portanto, domínio sobre o processo de seu trabalho nem sobre o produto deste, tornando-se um trabalhador alienado e, portanto, vulnerável às condições de apropriação privada impostas: 


\begin{abstract}
A propriedade privada resulta portanto, por análise, do conceito de trabalho exteriorizado (entäusserten), isto é, de homem exteriorizado (entäusserten), de trabalho estranhado (entfremdeten), de vida alienada (entfremdeten), de homem alienado (entfremdeten).

Herdamos certamente 0 conceito de trabalho exteriorizado (entäusserten) (de vida exteriorizada (entäusserten)) da economia nacional como resultado do movimento da propriedade privada. Mas evidencia-se na análise desse conceito que, se a propriedade privada aparece como fundamento, como razão do trabalho exteriorizado (entäusserten), ela é antes uma consequência do mesmo, assim como também os deuses são, originariamente, não a causa, mas o efeito do erro do entendimento humano. Mais tarde essa ação se transforma em ação recíproca. (MARX, 2008, pp. 87-88).
\end{abstract}

Pela divisão social do trabalho, a alienação fragmenta e hierarquiza a produção em funções de planejamento e execução, ou trabalho material para produção de coisas e trabalho intelectual para produção de ideias. Nesta divisão, o trabalhador braçal fica destituído dos meios de produção intelectual, sem direito a contribuir com a criação, passando a executar ações sobre as quais não tem qualquer domínio, conferindo autonomia às ideias (consciência) e passando a acreditar serem estas que criam a realidade.

Nesse sentido, a fragmentação se fortalece, dicotomizando e privilegiando as ações de planejamento em detrimento das ações de execução, passando as ideias a serem consideradas responsáveis pela constituição da realidade, mostrando-a não como realmente é, mas como aparenta. Consequência do trabalho alienado, o trabalhador equipara-se a uma mercadoria, ficando o desenvolvimento de suas potencialidades humanas em plano secundário. Assim, o trabalhador somente se faz importante como força de trabalho que pode ser comprada ou vendida conforme as necessidades do capital.

Em verdade, despojado de todas as condições necessárias à utilização autônoma de sua força de trabalho e, não tendo, além desta, outra mercadoria para vender, o trabalhador se transforma, assim numa mercadoria, estabelecendo com o patrão uma relação entre comprador e vendedor da força de trabalho, abrindo-se um novo período na história social humana no qual além dos bens necessários à vida humana, o próprio trabalhador passa a ser mercadoria. (GRANEMANN, 2009).

Sendo a alienação inerente à sociedade capitalista, em que a estrutura social se caracteriza na divisão social do trabalho e da apropriação 
dos bens coletivamente produzidos por uma classe, "as finalidades assim como os meios da educação subordinam-se à estrutura e dinâmica das relações entre as classes sociais". (LIBÂNEO, 1994, p.18).

Nesse processo de alienação, a apropriação e transmissão de conhecimentos e habilidades, elaboração histórica e coletiva, que encerram o patrimônio desenvolvido pela sociabilidade humana, se transmitem também de maneira desigual e alienante, rebaixando o desenvolvimento e a evolução humana.

Assim a educação, ação intrínseca das relações sociais e "meio pelo qual se desenvolvem o conhecimento, os valores, os aspectos éticos, a dimensão crítica, onde se desenvolvem aprendizados constantes e gradativos", que proporciona aos indivíduos a capacidade para formular, conhecer e estabelecer relações ativas e transformadoras em relação ao meio social, em vez de contribuir para humanização e emancipação social, na sociedade capitalista, acaba por se perder na divisão das tarefas, separando de forma hierárquica os saberes em ações de planejamento e execução, reflexo da divisão social do trabalho que separa trabalho manual do trabalho intelectual. (OLIVEIRA, 2007, p.22).

Integrante dessa sociedade com base na divisão de classe e fragmentação do trabalho socialmente produzido, a educação passa a se organizar de forma a atender as exigências do contexto produtivo, passando as profissões do ponto de vista da formação, "a ser classificadas de acordo com o nível de complexidade que, por sua vez, se relaciona com o nível de escolaridade necessário para o desenvolvimento de cada uma delas". (RAMOS, 2010, p.70).

Atendendo aos interesses da classe dominante, a educação bifurca sua forma e modalidade de disponibilização. Assim, para os filhos das elites, as instituições de ensino se caracterizam pelo ensino propedêutico, já para os filhos dos trabalhadores, ensino profissionalizante, este voltado à formação de uma força de trabalho psíquica e fisicamente adaptada às técnicas e à disciplina da produção para preparação de mão de obra para o mercado.

Espelhado na forma de organização do processo produtivo, o qual desenvolve apenas capacidades unilaterais do trabalhador, separando-o, atomizando-o e isolando-o para execução de funções específicas, sem domínio 
do processo produtivo total e conectado à sociedade, a educação reproduz essa lógica, privilegiando a transmissão do que já está pronto e acabado de forma fragmentada e especializada em disciplinas, sem qualquer vinculação, não deixando espaço para "compreensão das relações sociais de produção e do processo histórico e contraditório de desenvolvimento das forças produtivas". (RAMOS, 2010, p.67).

Por sua vez, a Ciência, desdobramento da educação e necessidades da produção material, desenvolvida de forma pura e centrada em descobertas de beneficio coletivo, é monopolizada, passando a ser utilizada de forma aplicada, estreitando os laços entre o mundo da produção e o mercado, transformando-se numa mercadoria adequada a serviço do capital. Conforme Marx,

Os conhecimentos, a compreensão e a vontade, que o camponês ou artesão autônomo desenvolve mesmo que em pequena escala, como o selvagem exercita toda arte da guerra como astúcia pessoal, agora passam a ser exigidos apenas pela oficina em seu conjunto. As potências intelectuais da produção ampliam sua escala por um lado, porque desaparecem por muitos lados. $O$ que os trabalhadores parciais perdem, concentra-se no capital com que se defrontam. É um produto da divisão manufatureira do trabalho opor-lhes as forças intelectuais do processo material de produção como propriedade alheia e poder que os domina. Esse processo de dissociação começa na cooperação simples, em que o capitalista representa em face dos trabalhadores individuais a unidade e a vontade do corpo social de trabalho. $O$ processo desenvolve-se na manufatura, que mutila 0 trabalhador, convertendo-o em trabalhador parcial, ele se completa na grande indústria, que separa do trabalho a ciência como potência autônoma de produção e a força a servir ao capital. (2004, p.283284).

Cabe destacar que a educação, muito embora tenha uma conotação ampla, realizando-se em todos os espaços da vida humana, em sua modalidade formal como escola, aluno e professor, surge quando a "educação se sujeita à pedagogia”, ou seja, quando situações próprias para o seu exercício são criadas e estabelecidos executores especializados para sua realização, associando também a estes métodos regras e tempos. (BRANDÃO, 1995, p.26).

É com a Revolução Industrial que se evidenciam os vínculos da educação com a produção da vida material, carecendo a vida produtiva de formação, passando o mercado a ser elemento indissociável e princípio ordenador do sistema de ensino, do currículo e das práticas pedagógicas, 
reproduzindo as relações sociais de produção e conformando os sujeitos à ordem da sociedade capitalista. A sociedade alienada/estranhada, longe de proporcionar o desenvolvimento integral dos trabalhadores em todas as suas potencialidades, os especializa, hierarquiza e os individualiza, num processo em que o outro deixa de ser visto como semelhante para ser um rival, um concorrente, num contínuo espaço de insegurança.

\section{CONSIDERAÇÕES FINAIS}

Neste texto, buscamos exprimir aspectos importantes das categorias trabalho e alienação, da perspectiva marxista, visando a subsidiar e fundamentar o debate quando da crítica da educação na sociedade atual, por defendermos a noção de que uma análise da educação que fuja da superficialidade, necessariamente, tem de estabelecer relações com a totalidade da vida material e visualizar as contradições e antagonismos de classe.

Muito embora outras categorias da tradição marxista sejam importantes quando da análise da educação, optamos neste texto por trabalho e alienação, por julgarmos serem estas imprescindíveis nas discussões, tendo em vista conterem em seu interior elementos que instigam o questionamento e a reflexão, propiciando a compreensão de que a sociedade de classes com base na apropriação privada dos meios de produção e divisão social do trabalho é resultado do processo histórico e, portanto, passível de transformação.

Em realidade, a ausência da compreensão da categoria trabalho, como categoria fundante da sociabilidade humana e elemento que permite ao homem transformar a sociedade ao tempo em que também se transforma, fragiliza o debate, contribuindo para que as análises de educação se façam esvaziadas de argumentos mais complexos e totalizantes. Por seu turno, a falta de compreensão de que a alienação está presente no cotidiano, sendo responsável pelo aparecimento do dominador e da propriedade privada, impedindo que os meios de produção, assim como o patrimônio propedêutico produzido se façam acessíveis de maneira democrática e socializada, também 
são aspectos que empobrecem os discursos, constituindo-se, estes, de maneira superficial.

Desta forma, analisar a educação na sociedade do capital numa perspectiva marxista é desvelar o conteúdo das relações materiais entre os homens, explicitando como estas se constituem no cotidiano e na totalidade da sociedade. É descortinar as contradições e antagonismos que permeiam à luta de classes, desnudando a exploração e as desigualdades provocadas pela relação entre o capital e o trabalho em sua relação com o processo educativo.

Uma análise da educação numa perspectiva marxista exige, assim, uma reflexão transposta aos mecanismos formais e sistematizados da educação escolar, que privilegiam conteúdos abstratos e fogem ao questionamento, à crítica e ao julgamento, num adestramento de conformismo e disciplinamento oriundos da ordem vigente. Exige reconhecer que a educação na sociedade de classes é utilizada para formação limitada e voltada para interesses de mercado, que, ao tempo em que aliena, fragmenta 0 conhecimento e o desvincula do cotidiano, prestando-se muito mais para seleção e repetição de ações rígidas do que para ampliação e intervenção no dia a dia.

Dentro da perspectiva marxista, a educação não é um processo de transferência de saberes, mas sim um processo dialético de conhecimento da realidade, pautado por um caráter libertador, questionador, que adentra a essência da realidade, desvendando a relação dialética entre objetividade e subjetividade da totalidade das manifestações cotidianas, não apenas na busca de explicações, mas também de intervenção e transformação na sociedade.

Para a perspectiva marxista, a educação deve ser um instrumento de mudança e de transformação da sociedade, e não de manutenção da ordem vigente, libertando o homem da opressão existente durante a produção e reprodução da vida social, fenômenos que, partindo da teleologia humana, deveria ser humanizador e não opressor.

Nesta emancipação, não há um antídoto ou uma pedra filosofal. Assim, uma das tarefas importantes da educação reporta-se a contribuir para descoberta de que elementos impedem a emancipação do homem, indicandoIhe as raízes sociais desses elementos para nega-los. Em verdade, é negando a organização material classista que a emancipação pode acontecer. 
Para Marx, são as contradições no contexto do desenvolvimento das forças produtivas que propiciam o reconhecimento do trabalhador quanto ao seu estado de opressão. Nesse sentido, atribui à classe trabalhadora a tarefa de transformação da sociedade capitalista numa outra sociabilidade, na qual os homens possam ser valorizados, não pela sua capacidade de produção material, mas por serem humanos dotados de capacidade criadora, capazes de se elevarem acima das necessidades materiais imediatas.

A educação em todo esse processo ocupa espaço fundamental no sentido de contribuir para ampliação da consciência do trabalhador quanto à situação de exploração vivenciada na sociedade de classe. Na generalização de uma educação que venha a contribuir para superação da formação unilateral, contudo, retrato da divisão social do trabalho, é uma tarefa que exige, por princípio, a base de uma consciência de classe.

Nessa perspectiva, debates e discursos que não levem em consideração o rompimento da sociabilidade humana que mantém a propriedade privada dos meios de produção e que reproduz a divisão social do trabalho, refletida numa educação para o conformismo e para a disciplina e ascensão social singular, continuarão esvaziados e fragilizados e contribuirão para fortalecimento e permanência da sociedade capitalista atual.

\section{REFERÊNCIAS}

BRANDÃO, Carlos Rodrigues. 0 que é educação. 33 ed. São Paulo: Brasiliense, 1995.

CURY, Carlos Roberto Jamil. Direito à educação: direito à igualdade, direito à diferença. Cad. Pesquisa, São Paulo, n. 116, July 2002.

GRANEMANN, Sara. O processo de produção e reprodução social: trabalho e sociabilidade. Programa de Pós-Graduação Latu Sensu em Serviço Social: direitos sociais e competências profissionais. CFESS/ ABEPSS/ CEAD-UnB Brasília, 2009.

LIBANEO, Jose Carlos. Didática. São Paulo: Cortez, 1994.

MARX, Karl. Manuscritos Econômico-filosóficos. São Paulo: Boitempo Editorial, 2008. 
2004.

, Karl. O Capital, Vol. 1/1. 22. ed. Rio de Janeiro: Civilização Brasileira,

, Karl; ENGELS, F. A Ideologia Alemã (I - Feuerbach). 6. ed. São Paulo: Hucitec, 1987.

NETTO, J. P. e BRAZ, M. Economia Política - uma introdução crítica. São Paulo: Cortez, 2008.

OLIVEIRA, Simone Barros de. Desenvolvimento sustentável e cultura de paz no meio escolar: desafios para o serviço social. Dissertação de mestrado apresentada a Faculdade de Serviço Social da Pontifícia Universidade Católica do Rio Grande do Sul, Porto Alegre, 2007.

RAMOS, M. N. Implicações políticas e pedagógicas da EJA integrada à Educação Profissional. Educação e realidade, v. 35, n. 1, p. 65-85, jan./abr. 2010.

SAVIANI, Dermeval. Trabalho e educação: fundamentos ontológicos e históricos. Revista Brasileira de Educação v. 12 n. 34 jan./abr. 2007.

\footnotetext{
${ }^{1}$ Assistente Social, doutoranda em Educação Brasileira pela Universidade Federal do Ceará. Professora do IFCE - Campus Iguatu, e-mail: adriana_as_ce@hotmail.com

${ }^{2}$ Pedagoga, Doutora em Educação Brasileira pela Universidade Federal do Ceará. Professora do IFCE - Campus Fortaleza, e-mail: elenilce@ifce.edu.br

${ }^{3}$ Arquiteto, Mestre em Sociologia, Doutor em Educação pela Universidade Federal do Ceará UFC. Professor da UFC, e-mail: eneas_arrais@hotmail.com

4 Muito embora exista no meio acadêmico uma discussão na qual se distinguem alienação/exteriorização de estranhamento, por considerar que na produção o trabalhador necessariamente se aliena e, portanto, se exterioriza, colocando algo de si nas objetivações, consideramos aqui alienação como estranhamento, ou seja processo no qual o trabalhador não se reconhece no que produz. Já por objetivações consideramos a atividade criativa, seja da relação entre o homem e a natureza, seja da relação dos homens entre si. A tradução da obra Manuscritos Econômicos e Filosóficos feita por Jesus Ranieri e editada pela Boitempo privilegia essa discussão na qual os termos alienação e objetivação são equivalentes, significando momentos positivos no desenvolvimento humano.
}

RECEBIDO EM: agosto/2013

APROVADO EM: setembro/2013 